\title{
Erratum to: Intelligence in Networks
}

Thongchai Yongchareon ${ }^{1}$, Finn Arve Aagesen ${ }^{2}$, and Vilas Wuwongse ${ }^{3}$

1 Telephone Organisation of Thailand, Thailand

2 Norwegian University of Science and Technology, Norway

3 Asian Institute of Technology, Thailand

\section{Erratum to: \\ T. Yongchareon et al. (Eds.) \\ Intelligence in Networks \\ DOI: $10.1007 / 978-0-387-35581-8$}

The book was inadvertently published with an incorrect name of the copyright holder. The name of the copyright holder for this book is: (c) IFIP International Federation for Information Processing. The book has been updated with the changes.

The updated original online version for this book can be found at DOI: $10.1007 / 978-0-387-35581-8$ 